\title{
Correspondence
}

\section{PhD supervisors: be better mentors}

As steering-committee members of the European Association of Students and Post-docs in Synthetic Biology, we find it questionable and unhelpful to blame research students for the breakdown in communication with supervisors (E. Diamandis Nature 544, 129; 2017).

We agree that $\mathrm{PhD}$ students should be proactive in their investigations and in using their supervisor's expertise. First, however, they need to find their feet. They are largely naive about the highly competitive nature of science when they start in a lab, and often have no experience of project management. $\mathrm{PhD}$ students are not trainees or employees: they need guidance and supervision, particularly during the first two years.

$\mathrm{PhD}$ students today face more challenges than most professors ever did. The supervisor has mentoring responsibilities beyond academic performance, including the student's wellbeing. Many PhD students crack under the strain of publishing pressures and deteriorating career prospects (see go.nature. com/2pt9q6j). Unless underpinned by appropriate support, meetings with the supervisor risk reinforcing the student's fear of failure.

European universities are tackling this problem by providing more courses and resources to train principal investigators in management and leadership. Their widespread requirement for $\mathrm{PhD}$ candidates to have completed a master's degree before enrolling means that students are better equipped to deal with the few islands of success in the sea of failures typical of the research environment.

Devang Mehta ETH Zurich, Switzerland.

Konstantinos Vavitsas

University of Copenhagen,

Denmark.

devang@ethz.ch

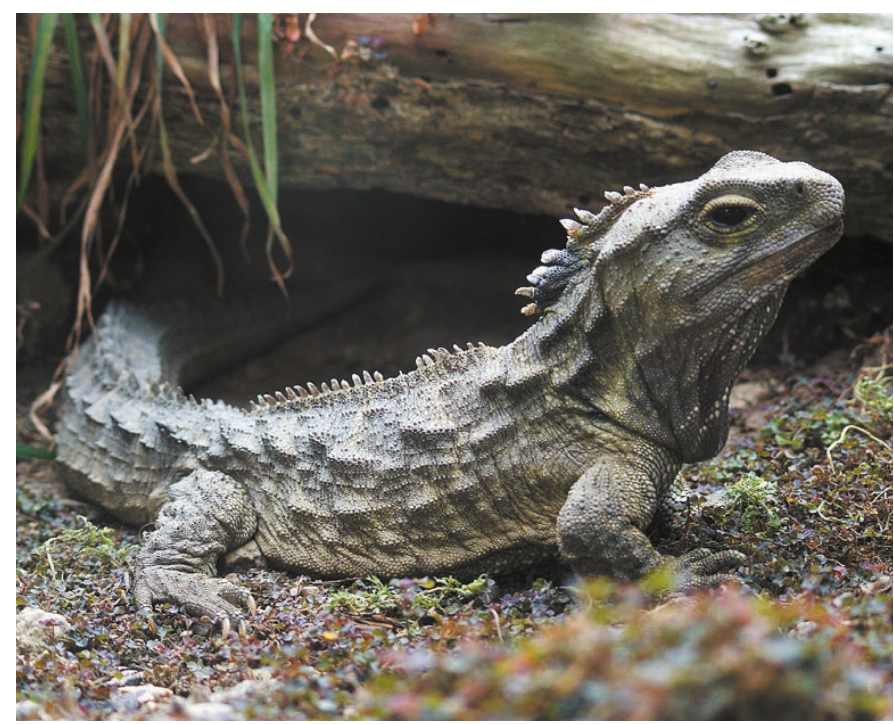

The tuatara (Sphenodon punctatus) can grow to lengths of 60 centimetres.

\section{PhD supervisors: invest more time}

A supervisor risks stoking a graduate student's "supervisor phobia" if he or she fails to invest the time and energy necessary to help them fulfil their potential (see E. Diamandis Nature 544, 129; 2017). Students flounder without structure, clear expectations, encouragement, accountability and guidance. This can give rise to mental-health issues, causing them to distance themselves from supervisors (see, for example, K. Levecque et al. Res. Policy 46, 868-879; 2017).

Meet with your students at least twice every month. Ask about their projects, what they are proud of, what they have found more difficult than anticipated, and what roadblocks are in their way. Enquire about how they want to develop as scientists, what other types of mentor they would like to connect with and what they do when they are not in the lab. Decide on a plan that enables them to receive feedback between meetings. Help them to set specific research and professional goals.

David A. McDonald Duke

University, Durham, North Carolina, USA. dave.mcdonald@duke.edu

\section{Agree on definitions of synchrony}

Synchronous phenomena are central to many fields, including technology, finance, molecular biology, physics, music and psychology (see Supplementary Information for references). Yet conceptual inconsistencies are thwarting the upsurge of interest in this ubiquitous topic, which a shared definition of synchrony could address.

Synchrony is often taken to mean loose coordination patterns among processes, individuals or populations tidal rhythms and animals' mating behaviours are examples. In this guise, synchrony has teleological and mechanistic connotations. Alternatively, synchrony can refer to the precise coincidence of events in time, such as two photons reaching a sensor or musicians playing in unison.

Conflating different meanings generates confusion and misinterpretation. It is time to engage in an interdisciplinary debate and converge on common definitions. We might, for instance, adopt the most restrictive definition of synchrony - already used in mathematics and physics — and appropriately qualify looser forms of co-occurrence. This would endow the life sciences and social sciences with the quantitative tools that mathematics has been refining for decades.

Andrea Ravignani Sealcentre Pieterburen, the Netherlands. andrea.ravignani@gmail.com See go.nature.com/2p8ybp for a full list of references.

\section{Sole survivor of a once-diverse lineage}

The tuatara of New Zealand (Sphenodon punctatus; pictured), formerly thought to be a lizard, was recognized 150 years ago this month as the only living member of its own reptile group Rhynchocephalia (A. Günther Phil. Trans. R. Soc. 157, 595629; 1867).

The tuatara's ancestors separated from those of lizards and snakes (Squamata) around 240 million years ago. The frame-like skull of $S$. punctatus, long believed to be an archaic feature, is in fact a specialization for supporting its powerful jaws (D. I. Whiteside Phil. Trans. R. Soc. Lond. B 312, 379-430; 1986).

The animal's taxonomic isolation has turned it into a flagship species for studies of evolution, biodiversity and conservation (see, for example, A. Cree Tuatara Canterbury Univ. Press; 2014).

Marc E. H. Jones University of Adelaide, Australia.

Mark N. Hutchinson South Australian Museum, Adelaide, Australia. marc.jones@adelaide.edu.au

\section{CONTRIBUTIONS}

Correspondence may be sent to correspondence@ nature.com after consulting go.nature.com/cmchno. Alternatively, readers may comment online: www. nature.com/nature. 